\title{
CARDIAC AUTONOMIC NEUROPATHY IN CHILDREN AND ADOLESCENTS WITH TYPE 1 DIABETES MELLITUS: PREVALENCE AND RELATION TO DURATION AND CONTROL OF DIABETES.
}

1. MBBS, DCH, FCPS (Paediatrics) Associate Professor Paediatric Endocrinology

Children Hospital \& Institute of child health, Multan

2. MBBS, FCPS (Paediatrics), FCPS (Paediatric Cardiology).

Associate Professor Paediatric Cardiology

Children Hospital \& Institute of Child Health, Multan.

3. MBBS, FCPS (Paediatrics)

Women Medical Officer

Children Hospital \& Institute of Child Health, Multan.

4. MBBS, FCPS (Paediatrics)

Medical Officer

Children Hospital \& Institute of Child Health, Multan.

Correspondence Address:

Dr. Waqas Imran Khan

H No. 136 Doctors Street, Jinnah Town

Opp. To 7up Factory, District Jail Road,

Multan.

drwaqas69@hotmail.com

Article received on:

$14 / 02 / 2020$

Accepted for publication:

$13 / 05 / 2020$

\begin{abstract}
Waqas Imran Khan', Muhammad Sohail Arshad², Sidra Anjum ${ }^{3}$, Sohail Anjum ${ }^{4}$
\end{abstract}
ABSTRACT... Objectives: The objective of this study is to find the clinical characteristics and frequency of CAN in T1DM and its relationship with glycemic control and duration of diabetes. Study Design: Observational Cross Sectional study. Setting: At Department of Pediatric Endocrinology and Cardiology at The Children's Hospital and Institute of Child Health (CH \& ICH) Multan. Period: June 2019 to December 2019. Materials \& Methods: A total of 90 children and adolescents of 10-15 years with T1DM were enrolled in this study after taking informed consent. Each study participant had blood pressure measured in supine and standing position for postural hypotension. Heart rate variation during Valsalva maneuver (15 seconds) and deep respiration were recorded. Resting heart rate was also measured by ECG in quite room when the patient was relaxed. Glycemic control was assessed by HbA1C level. Results: Among diabetic children $51.1 \%(n=46)$ were males. Age range was $10-15$ years with mean of $12.6 \pm 1.7$ years. CAN was diagnosed in $12(13.6 \%)$ of diabetic children. Significant relationship of CAN was seen in fair control 4 (33.3\%) and poor glycemic control patients $8(66.6 \%)$ compared to intensive glycemic control $(n=0,0 \%)$ p value 0.063 as well as longer duration of diabetes 9 (75\%) p value 0.052 . Conclusion: The prevalence of CAN was $13.6 \%$ among T1DM in our study. CAN is common with poor glycemic control and longer duration of diabetes. CAN should be routinely evaluated in T1DM.

Key words: $\quad$ Cardiac Autonomic Neuropathy, Diabetes Mellitus Type 1, Glycemic Control, Valsalva Maneuver.

Article Citation: Khan WI, Arshad MS, Anjum S, Anjum S. Cardiac autonomic neuropathy in children and adolescents with Type 1 diabetes mellitus: Prevalence and relation to duration and control of diabetes. Professional Med J 2020; 27(10):2138-2142. DOI: 10.29309/TPMJ/2020.27.10.4522

\section{Introduction}

Diabetes mellitus type 1 (T1DM) is an endocrine disorder and worldwide over 50000 children are suffering from this condition. ${ }^{1}$ Due to its increase in prevalence, morbidity and mortality it is a serious health issue. Diabetic autonomic neuropathy (DAN) is a known problem of T1DM and affects various vital organs of the body like cardiovascular, gastrointestinal, genitourinary, respiratory, neurovascular, neuroendocrine and pupillomotor. ${ }^{2}$ DAN cause dysfunction of sympathetic and parasympathetic nervous system and although clinically it appears late but subclinical DAN can appear within 2 years in T1DM $^{3}$

The pathogenesis of DAN including cardiac autonomic neuropathy (CAN) and diabetic peripheral neuropathy are similar. These consist of oxidative stress, advanced glycation end products (AGE), vitamin deficiencies and neurovascular insufficiency. ${ }^{4,5,6}$

Mortality due to CAN increases due to arrhythmias, myocardial ischemia and sudden death. ${ }^{7,8}$ It may lead to prolongation of QT interval which leads to arrthymias. Earliest sign of CAN may be change in heart rate variability. Other clinical manifestations of CAN are exercise intolerance, sinus tachycardia, bradycardia, and no alteration in heart rate during daily activities. It can be diagnosed by evaluation of resting tachycardia, loss of sinus rhythm and heart rate response to Valsalva maneuver. It can be diagnosed if two among three of the above features are abnormal. Most of the DAN are thought to be irreversible, 
however CAN improves with improved glycemic control. $^{9}$

The objective of this study is to find the clinical characteristics and frequency of CAN in T1DM and its relationship with glycemic control and duration of diabetes.

\section{MATERIAL \& METHODS}

This descriptive cross-sectional study was done in department of pediatric endocrinology and cardiology from June 2019 to December 2019 at The $\mathrm{CH} \& \mathrm{ICH}$ Multan. Ninety children and adolescents of 10-15 years old with T1DM were included in this study after taking informed consent from patients/ parents. All patients having acute diabetic complications like hypoglycemia or diabetic ketoacidosis, known cardiac disease or taking medicines for cardiac disease were excluded from this study. Baseline characteristics were collected on a predesigned structured Performa. Diagnosis of T1DM was according to American diabetic association (ADA) criteria. $^{10}$

Patients were advised not to drink tea, coffee or eat chocolate at least 12 hours before study. Standard tests were used to diagnose CAN which were devised by Ewing and clark. ${ }^{11}$ CAN was diagnosed when at least two tests were pathological. ${ }^{11}$

\section{Heart rate response to Valsalva maneuver}

In this test patient was asked to blow against syphmomanometer for 15 seconds at a pressure of $40 \mathrm{~mm}$ of mercury. ECG was recorded during the procedure. Longest and shortest RR intervals were used to calculate Valsalva ratio and was taken as (normal > 1.2, borderline 1.11-1.2 and abnormal $<1.10$.)

\section{Heart rate variation during deep breathing}

Patient was asked to take deep breaths (6 breaths/min) with ECG recording. Longest and shortest R-R intervals were calculated as beats per minute. R-R variation is normal $>15$ beats/minute, borderline $10-15$ beats/min and diagnostic $<10$ beats/min.

\section{Postural hypotension}

This test was performed by measuring blood pressure (BP) using mercury sphygmomanometer on lying down and standing up with fall in systolic BP as (normal < $10 \mathrm{~mm} \mathrm{Hg}$, borderline 11-29 mm $\mathrm{Hg}$ and diagnostic $>30 \mathrm{~mm} \mathrm{Hg}$ ).

\section{Resting heart rate (HR)}

$\mathrm{HR}$ was calculated when the patient was relaxed in quite room. Resting tachycardia was diagnosed as HR >100 beats per minute.

High-performance liquid chromatography method was used to measure glycosylated hemoglobin $(\mathrm{HbA} 1 \mathrm{C})$. Glycemic control was good (HbA1C 6-7.9), fair (HbA1C 8-9.9) and poor $(\mathrm{HbA} 1 \mathrm{C}>10) .{ }^{12}$

The data was analyzed by Statistical Program for Social Science software (SPSS, Chicago, IL, USA), version 20.0 for windows. Quantitative variables are presented as mean and standard deviation (SD). Qualitative variables are represented as frequency and percentages. Relationship of CAN with glycemic control and duration of diabetes was assessed by Chi-square test. $P$ value less than or equal to 0.5 is taken as statistically significant. Institutional Ethical committee of $\mathrm{CH}$ \& $\mathrm{ICH}$, Multan had approved this study.

\section{RESULTS}

Demographic data of T1DM children is shown in Table-I. Ninety patients with T1DM were included in this study with $46(51.1 \%)$ males and 44 (48.9\%) females. Patient's age range was $10-15$ years with mean age and standard deviation was $12.7 \pm 1.7$ years. Mean duration of diabetes was $4.9 \pm 2.7$ years. Good glycemic control was observed in 20 (22.2\%), fair control in 29 (32.2\%) and poor control in 41 (45.5\%).

CAN was diagnosed in 12 (13.6\%) of patients. Heart rate response to deep respiration was abnormal in 5 (5.5\%). Heart rate response to Valsalva maneuver was abnormal in 11 (12.2\%). Similarly postural hypotension and resting heart rate were abnormal in 12 (13.3\%) and 14 (15.5\%) respectively (Table-II). Frequency of CAN was higher in fair control 4 (33.3\%) and poor control 
$8(66.6 \%)$ compared to good glycemic control 0 $\% \mathrm{p}$-value 0.063 . CAN was significantly related to longer duration of diabetes ( $>5$ years) (Table-III).

\begin{tabular}{|c|c|c|c|c|}
\hline \multicolumn{2}{|c|}{$\begin{array}{l}\text { Mean age \& std deviation } \\
\text { Age Range }\end{array}$} & \multicolumn{3}{|c|}{$\begin{array}{l}12.7 \pm 1.7 \text { years } \\
10-15 \text { years }\end{array}$} \\
\hline \multicolumn{2}{|c|}{ Male } & \multicolumn{3}{|c|}{$46(51.1 \%)$} \\
\hline \multicolumn{2}{|l|}{ Female } & \multicolumn{3}{|c|}{$44(48.9 \%)$} \\
\hline \multicolumn{5}{|l|}{ Glycemic control } \\
\hline \multicolumn{2}{|l|}{ Good control } & \multicolumn{3}{|c|}{$20(22.2 \%)$} \\
\hline \multicolumn{2}{|l|}{ Fair control } & \multicolumn{3}{|c|}{$29(32.2 \%)$} \\
\hline \multicolumn{2}{|l|}{ Poor control } & \multicolumn{3}{|c|}{$41(45.5 \%)$} \\
\hline \multicolumn{5}{|c|}{ Duration of diabetes } \\
\hline \multicolumn{2}{|l|}{$>5$ years } & \multicolumn{3}{|c|}{$41(45.6 \%)$} \\
\hline \multicolumn{2}{|l|}{$<5$ years } & \multicolumn{3}{|c|}{49 (54.4\%) } \\
\hline \multicolumn{5}{|c|}{$\begin{array}{l}\text { Table-I. Demographic data of patients with TIDM } \\
\qquad(\mathrm{N}=90)\end{array}$} \\
\hline \multicolumn{2}{|l|}{ CAN Parameter } & \multicolumn{3}{|c|}{ N90, (100 \%) } \\
\hline \multicolumn{2}{|c|}{ HR response to deep respiratio } & \multicolumn{3}{|c|}{$5(5.5 \%)$} \\
\hline \multicolumn{3}{|c|}{ HR response to valsalva maneuver } & \multicolumn{2}{|c|}{$11(12.2 \%)$} \\
\hline \multicolumn{2}{|c|}{ Postural hypotension } & \multicolumn{3}{|c|}{$12(13.3 \%)$} \\
\hline \multicolumn{2}{|c|}{ Resting HR } & \multicolumn{3}{|c|}{$14(15.5 \%)$} \\
\hline \multicolumn{5}{|c|}{$\begin{array}{l}\text { Table-II. Cardiac autonomic neuropathy results in } \\
\text { study patients }(\mathrm{N}=90)\end{array}$} \\
\hline $\begin{array}{l}\text { Glycemic } \\
\text { Control }\end{array}$ & $\begin{array}{l}\text { CAN } \\
\text { Positive }\end{array}$ & & $\begin{array}{l}\text { CAN } \\
\text { egative }\end{array}$ & P-Value \\
\hline Good $(n=20)$ & 0 & & $0(25.7)$ & \multirow{3}{*}{0.063} \\
\hline Fair $(n=29)$ & $4(33.3 \%)$ & 25 & $(32.0 \%)$ & \\
\hline Poor $(n=41)$ & $8(66.6 \%)$ & 33 & $(42.3 \%)$ & \\
\hline \multicolumn{4}{|c|}{ Duration of Diabetes } & \multirow{3}{*}{0.052} \\
\hline$<5$ years $(n=41)$ & $3(25 \%)$ & 38 & $(48.7 \%)$ & \\
\hline$>5$ years $(n=49)$ & $9(75 \%)$ & 40 & $(51.3 \%)$ & \\
\hline \multicolumn{5}{|c|}{$\begin{array}{c}\text { Table-III. CAN correlation with glycemic control and } \\
\text { duration of diabetes }\end{array}$} \\
\hline
\end{tabular}

\section{DISCUSSION}

Autonomic neuropathy involves various organs of the body that is why its manifestations are heterogenous. These can be seen in other diseases, beside diabetes like paraneoplastic disorders, toxic substances, degenerative diseases and cardiovascular diseases. ${ }^{13}$ Cardiac autonomic neuropathy carries high risk to mortality and morbidity and slowly progress over time. Subclinical CAN can persist for many years before it clinically manifests. ${ }^{14,15}$
The prevalence of CAN varies widely between various studies. In community based studies, prevalence is lower as compared to hospital based studies. In our study the prevalence of CAN was $13.5 \%$ which is in consistent with other studies. Pavy-Le et al ${ }^{16}$ and Aman et al. ${ }^{17}$ reported prevalence of $12.5 \%$ and $24 \%$ respectively. Whereas Paries et al. ${ }^{18}$ reported that it varies between 20 to $70 \%$.

CAN caries a poor prognosis and increases mortality as it causes cardiac ischemia, prolongation of QTC interval, poor ejection fraction, exercise intolerance and sudden death. ${ }^{19}$ Glycemic control has profound effect on the progression of CAN. Intensive glycemic control is essential as shown in The Diabetes Control and Complication Trial (DCCT) that it reduces the prevalence of CAN by $53 \% .{ }^{20}$ Similarly in our study CAN was more prevalent in fair and poor control diabetic children as compared to good control patients. As reported by DCCT the complications are reduces with strict glycemic with mean blood glucose of $155 \mathrm{mg} / \mathrm{dl}$ and mean $\mathrm{HbA} 1 \mathrm{c}$ of $7.2 \%$.

Furthermore in our study CAN was more prevalent in longer duration of diabetes ( $>5$ years). Young et $\mathrm{al}^{21}$ also described correlation of nerve dysfunction and duration of diaberes. In contrast Verrotti et al. ${ }^{22}$ did not find correlation between CAN with duration of diabetes and glycemic control.

To summarize, in this study CAN in present during early stages of T1DM children and adolescents. Strict glycemic control is essential to halt the onset of CAN, improving disease outcome and quality of life. Public awareness campaigns might help in better management of T1DM.

\section{CONCLUSION}

The outcome of our study documents high prevalence of CAN in type 1 diabetic children and adolescents during early stages of disease. Intense diabetic control is essential for better patient outcome. Public awareness campaigns and patient's realization that good diabetic control has a pivotal role for better outcome of this disease. We recommend routine evaluation 
for CAN in TIDM especially over 5 years duration of disease.

\section{Copyright(C) 13 May, 2020.}

\section{REFERENCES}

1. Patterson C, Guariguata L, Dahlquist G, SolteÂsz G, Ogle G, Silink M. Diabetes in the young-a global view and worldwide estimates of numbers of children with type 1 diabetes. Diabetes Res Clin Pract. 2014; 103:161-75. doi: 10.1016/j.diabres.2013.11.005 PMID: 24331235 .

2. Vučković-Rebrina S, Barada A, Smirčić-Duvnjak L. Diabetic autonomic neuropathy. Diabetol Croat. 2013; 42(3):73-79.

3. Trotta D, Verrotti A, Salladini C, Chiarelli F. Diabetic neuropathy in children and adolescents. Pediatr Diabetes.2004; 5(1):44-57.

4. Cameron NE, Cotter MA. Metabolic and vascular factors in the pathogenesis of diabetic neuropathy. Diabetes. 1997; 46(Suppl 2):S31-S37.

5. Hoeldtke RD, Bryner KD, McNeill DR, Hobbs GR, Riggs JE, Warehime SS, et al. Nitrosative stress, uric acid, and peripheral nerve function in early type 1 diabetes. Diabetes. 2002; 51(9):2817-2825.

6. Low PA, Nickander KK, Tritschler HJ. The roles of oxidative stress and antioxidant treatment in experimental diabetic neuropathy. Diabetes. 1997 46(Suppl 2):S38-S42.

7. Maser RE, Mitchell BD, Vinik Al, Freeman R. The association between cardiovascular autonomic neuropathy and mortality in individuals with diabetes: A meta- analysis. Diabetes Care. 2003; 26(6): 1895-1901.

8. Pop-Busui R. Cardiac autonomic neuropathy in diabetes: A clinical perspective. Diabetes Care. 2010; 33(2):434-441.

9. Aring $\mathrm{AM}$, Jones $\mathrm{DE}$, Falko JM. Evaluation and prevention of diabetic neuropathy. Am Fam Physician. 2005; 71:2123-8.

10. American Diabetes Association. Diagnosis and classification of diabetes mellitus. Diabetes Care. 2010; 33 Suppl 1:S62-9.

11. Ewing DJ, Martyn CN, Young RJ, Clarke BF. The value of cardiovascular autonomic function tests: 10 years experience in diabetes. Diabetes Care 1985; 8: 491-8.
12. Parks JS. The endocrine system. In: Kliegman RM, Jenson HB, Behrman RE, Stanton BF. Nelson text book of Pediatrics. Philadelphia, PA Saunders Elsevier; 2004.p. 1845-1972.

13. Vučković-Rebrina $S$, Barada A, Smirčić-Duvnjak L. Diabetic autonomic neuropathy. Diabetol Croat. 2013; $42(3): 73-79$.

14. Maser RE, Mitchell BD, Vinik Al, Freeman R. The association between cardiovascular autonomic neuropathy and mortality in individuals with diabetes: A meta- analysis. Diabetes Care. 2003; 26(6):1895-1901.

15. Pop-Busui R. Cardiac autonomic neuropathy in diabetes: A clinical perspective. Diabetes Care. 2010 33(2):434-441.

16. Pavy-Le Traon A, Fontaine S, Tap G, Guidolin B, Senard $\mathrm{JM}$, Hanaire H. Cardiovascular autonomic neuropathy and other complications in type 1 diabetes. Clin Auton Res. 2010; 20: 153-60.

17. Aman J, Eriksson E, Lideen J. Autonomic nerve function in children and adolescents with insulindependent diabetes mellitus. Clin Physiol. 1991; 11: 537-43.

18. Valensi P, Paries J, Attali JR, French Group for Research and Study of Diabetic Neuropathy. Cardiac autonomic neuropathy in diabetic patients: influence of diabetes duration, obesity, and microangiopathic complications-the French multicenter study. Metabolism 2003; 52:815-20.

19. Jalal S, Alai MS, Khan KA, Jan VM, Rhather RA, Iqbal $\mathrm{K}$, et al. Silent myocardial ischemia and cardiac autonomic neuropathy in diabetics. J Assoc Physicians India 1999; 47:767-9.

20. Diabetes Control and Complication Trial Research Group. The effect of intensive diabetes therapy on the development and progression of neuropathy. Ann Intern Med. 1995; 122:561-8.

21. Young RJ, Ewing DJ, Clarke BF. Nerve function and metabolic control in teenage diabetics. Diabetes. 1983; 32(2):142-147.

22. Verrotti A, Chiarelli F, Blasetti A, Morgese G. Autonomic neuropathy in diabetic children. J Paediatr Child Health. 1995; 31(6):545-548. 


\section{AUTHORSHIP AND CONTRIBUTION DECLARATION}

\begin{tabular}{|c|l|l|l|}
\hline Sr. \# & \multicolumn{1}{|c|}{ Author(s) Full Name } & \multicolumn{1}{|c|}{ Contribution to the paper } & Author(s) Signature \\
\hline 1 & Waqas Imran Khan & $\begin{array}{l}\text { Literature search study design, } \\
\text { Data acquisition, Final approval. } \\
\text { Data acquisition critical review, } \\
\text { Final approval. } \\
\text { Data acquisition, critical review, }\end{array}$ \\
3 & M. Sohail Arshad & Sidra Anjum & $\begin{array}{l}\text { Final approval. } \\
\text { Data acquisition, critical review, } \\
\text { Final approval. }\end{array}$ \\
\hline 4 & Sohail Anjum &
\end{tabular}

